Polymer Journal, Vol. 39, No. 10, pp. 1060-1064 (2007)

(C) 2007 The Society of Polymer Science, Japan

\title{
Preparation of Porous PVDF Nanofiber from PVDF/PVP Blend by Electrospray Deposition
}

\author{
Muhamad Nasir, ${ }^{1}$ Hidetoshi Matsumoto, ${ }^{1}$ Mie Minagawa, ${ }^{1}$ \\ Akihiko TANIOKA, ${ }^{1, \dagger}$ Tetsuya DANNO, ${ }^{2}$ and Hideo HORIBE ${ }^{3}$ \\ ${ }^{1}$ Department of Organic and Polymeric Materials, and International Research Center of Macromolecular Science, \\ Tokyo Institute of Technology, Mail Box S8-27, 2-12-1 Ookayama, Meguro-ku, Tokyo 152-8552, Japan \\ ${ }^{2}$ Department of Lifestyle Design, Kochi Women's University, 5-15 Eikokuji-cho, Kochi 783-8015, Japan \\ ${ }^{3}$ Research Laboratory of Integrated Technology Systems, Kanazawa Institute of Technology, \\ 3-1 Yatsukaho, Hakusan 924-0838, Japan
}

(Received May 8, 2007; Accepted July 11, 2007; Published August 28, 2007)

\begin{abstract}
Nanofiber with porous structures were prepared by electrospray deposition (ESD) from poly(vinylidene fluoride) (PVDF)/poly(vinylpyrrolidone) (PVP) blend and subsequent selective removal of PVP. In the present work, the effect of blending ratio of PVDF/PVP on formation of the pore and crystal structure of residual PVDF fiber was investigated. The residual PVDF nanofiber showed a higher specific surface area (the highest specific surface area was $28.54 \mathrm{~m}^{2} / \mathrm{g}$ from PVDF/PVP $=67 / 33 \mathrm{w} / \mathrm{w}$ ). The Fourier transform infrared spectroscopy and wide angle X-ray diffraction measurement also showed that selective removal of PVP enhanced the formation of $\beta$-phase crystal structure in PVDF nanofiber $(\beta$-phase content $>90 \%)$. [doi:10.1295/polymj.PJ2007037]

KEY WORDS Electrospray Deposition / Nanofiber / Poly(vinylidene fluoride) / Poly(vinylpyrrolidone) / Selective Extraction / Porous Structure / Crystalline Structure /
\end{abstract}

Recently, nanofiber and mat with high specific surface area have attracted much attention for the application such as filter media, ${ }^{1}$ protective clothing, ${ }^{2}$ aerospace, ${ }^{3}$ electronic device, ${ }^{4}$ tissue engineering, ${ }^{5}$ sensors, ${ }^{6}$ and biomedical uses. ${ }^{7}$ In addition, these applications could be greatly enhanced by the increasing the surface area and porosity of fibers.

Electrospray deposition (ESD) is the electric field induced spray processing and a versatile method for preparation of nano-microscaled fiber. ${ }^{8}$ Most of approaches for introducing porous structure into the bulk on a nanofiber relied on (i) the ESD of blends or composite followed by selective removal of one component, ${ }^{9,10}$ and (ii) phase separation based on evaporation of solvent or in the presence of vapor during ESD. ${ }^{11,12}$ Here, we attempt to prepare porous polymeric nanofiber from polymer blend by using a former approach.

Poly(vinylidene fluoride) (PVDF) is widely used for industrial applications because of its excellent chemical stability, mechanical strength, and ferroelectricity. PVDF has several crystalline structures: $\alpha, \beta$, and $\gamma$-phase, based on the chain conformation as trans or gauche linkages. ${ }^{13}$ The $\alpha$-phase is the most energetic stable state and $\beta$-phase has useful piezoelectric and pyroelectric properties. ${ }^{14,15}$ Our previous study showed that the addition of ionic surfactants remarkably enhanced the formation of $\beta$-phase structure of PVDF nanofiber during ESD process. ${ }^{16}$ Poly(vinyl pyrrolidone) (PVP), which is amorphous and water soluble polymer, is commonly used as additive to control the pore structure in preparation of polymeric membranes. ${ }^{17}$ In the ESD process, PVP is also effective for controlling the pore structure. ${ }^{18}$ The electret fibers due to their polar structure can enhance the collection efficiency of aerosol for not only charged aerosol but also uncharged aerosol. ${ }^{19}$ In addition, the pore structure inside nanofiber increases the specific surface area. Therefore, porous PVDF nanofiber with high $\beta$-phase content is expected as material for high efficiency filter media.

The aim of present work is to investigate the effects of blending ratio of PVDF/PVP and selective removal of PVP on formation of pore and crystal structure of residual PVDF nanofiber.

\section{EXPERIMENTAL}

\section{Materials}

Poly(vinylidene fluoride) (PVDF, $\mathrm{M}_{\mathrm{w}}=141,000$, KF1100) was obtained from Kureha, Japan. Poly(vinyl pyrrolidone) (PVP, $\left.\mathrm{M}_{\mathrm{w}}=35,000\right)$ and $\mathrm{N}, \mathrm{N}$-dimethyl acetamide (DMAc) were from Wako, Japan. Before use, PVDF was dissolved in N,N-dimethylformamide at $60^{\circ} \mathrm{C}$ and the precipitated in methanol. Thereafter PVDF was washed with methanol and vacuum-dried for $24 \mathrm{~h}$. Other reagents were used without further purification.

${ }^{\dagger}$ To whom correspondence should be addressed (Tel: +81-3-5734-2426, Fax: +81-3-5734-2876, E-mail: tanioka.a.aa@m.titech.ac.jp). 
A spray solution was prepared as follows: PVDF and PVP were dissolved in DMAc at various compositions: the total polymer concentration is fixed at $30 \mathrm{wt} \%$ and the blending ratio of PVDF/PVP is 83/ 17, 67/33, 50/50, 33/67 w/w. The PVDF/PVP solution was stirred at $60^{\circ} \mathrm{C}$ for several hours and then cooled to room temperature.

\section{Electrospray Deposition (ESD)}

The ESD device consist of syringe-type infusion pump (MCIP-III, Minato Concept, Japan), a high voltage regulated DC power supply (HDV-20K 7.5Std, Pulse Engineering, Japan), and grounded collector (aluminium sheet). ${ }^{8}$ The polymer solution was contained in a syringe with stainless steel needle (1.0 $\mathrm{mm}$ internal diameter). The applied voltage was 15 $\mathrm{kV}$, the distance from the tip of needle to collector was $12 \mathrm{~cm}$, and the flow rate of solution was $2 \mu \mathrm{l} / \mathrm{min}$.

\section{Selective removal of $P V P$}

To remove PVP, the as-deposited PVDF/PVP fiber was immersed in distilled water at $60^{\circ} \mathrm{C}$ for $1 \mathrm{~d}$ and then vacuum-dried for $1 \mathrm{~d}$.

\section{Characterization of fibers}

The surface morphologies of as-deposited PVDF/ PVP fiber and the residual PVDF fiber were observed by using a scanning electron microscope (SEM, SM200, Topcon, Japan) operated at $10 \mathrm{kV}$. All the SEM samples were sputtered-coated with Au. The average fiber diameter was analyzed from the SEM image using Adobe Photoshop 7.0 Software (Adobe, USA). The crystallinity of the nanofiber was measured by differential scanning calorimeter (DSC 6100, Seiko Instruments, Japan). Crystalline structure of the nanofiber was analyzed by a Fourier transform infrared spectrometer (FI-IR-410, Jasco, Japan) and X-ray diffraction (MiniFlex, Rigaku, Japan). Adsorption isotherm and the Brunauer-Emmet-Teller (BET) specific surface area $^{18}$ of the as-deposited PVDF/PVP fiber and the residual PVDF fiber were determined using an adsorption apparatus (ASAP 2010, micrometrics, USA). Nitrogen was selected as probe molecule. To specify the pore size on the residual PVDF fiber, mercury porosimetery measurement was carried by an instrument (AutoPore IV 9520, Micrometrics, USA).

\section{RESULT AND DISCUSSION}

\section{Morphology of nanofiber}

Figures 1 and 2 show the morphologies and fiber diameter of PVDF/PVP fiber before and after selective removal of PVP, respectively. Diameter of fiber is in the range of $200-800 \mathrm{~nm}$. Removal of PVP influenced on morphology and fiber diameter: average
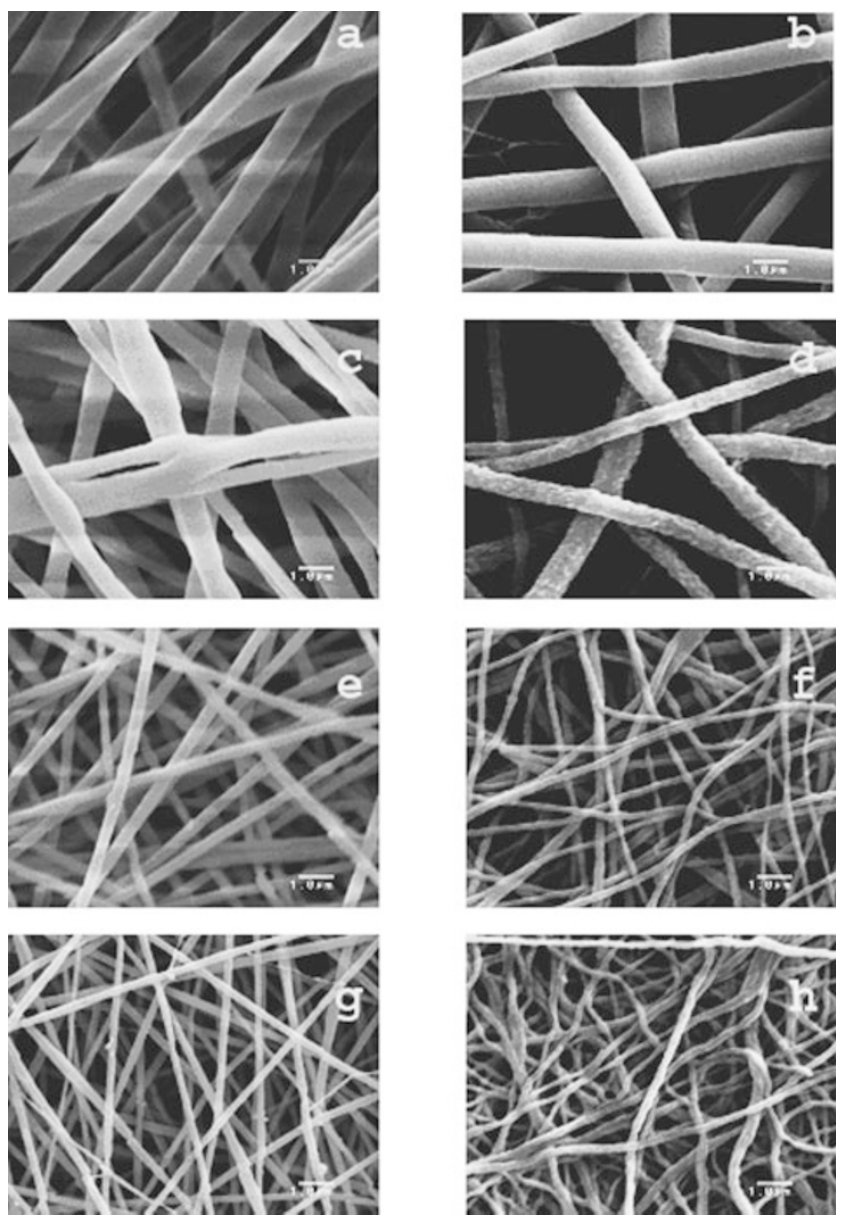

Figure 1. Surface SEM images of as-deposited PVDF/PVP fibers with various blending ratios and their residual PVDF fibers after removal of PVP. (a) PVDF/PVP $=83 / 17$, (b) PVDF from $\mathrm{PVDF} / \mathrm{PVP}=83 / 17$, (c) $\mathrm{PVDF} / \mathrm{PVP}=67 / 33$, (d) $\mathrm{PVDF}$ from $\mathrm{PVDF} / \mathrm{PVP}=67 / 33$, (e) $\mathrm{PVDF} / \mathrm{PVP}=50 / 50$, (f) $\mathrm{PVDF}$ from $\mathrm{PVDF} / \mathrm{PVP}=50 / 50$, (e) $\mathrm{PVDF} / \mathrm{PVP}=33 / 67$, and (f) $\mathrm{PVDF}$ from $\mathrm{PVDF} / \mathrm{PVP}=33 / 67$.

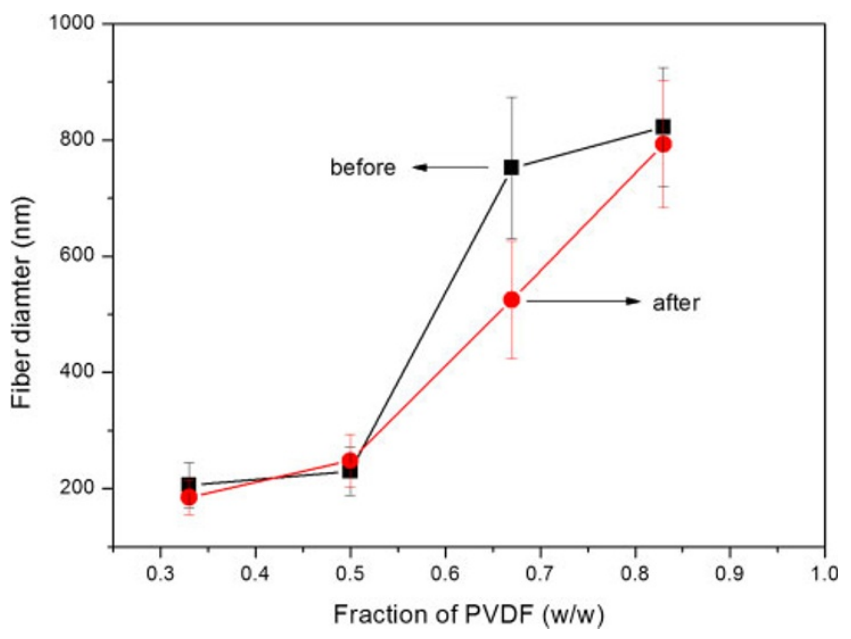

Figure 2. Effect of blending ratio of PVDF/PVP on fiber diameter of as-deposited PVDF/PVP fiber and residual PVDF fiber. 
Table I. The melting point and total crystalinity of nanofiber

\begin{tabular}{lcc}
\hline Samples & Tm $\left({ }^{\circ} \mathrm{C}\right)$ & Crystallinity $(\%)$ \\
\hline As-deposited PVDF & 172.0 & 65 \\
As-deposited PVDF $/ \mathrm{PVP}=83 / 17$ & 163.0 & 47 \\
As-deposited PVDF/PVP $=67 / 33$ & 164.5 & 17 \\
As-deposited PVDF $/ \mathrm{PVP}=50 / 50$ & 154.1 & 12 \\
As-deposited PVDF $/ \mathrm{PVP}=67 / 33$ & 153.4 & 6 \\
Residual PVDF from PVDF $/ \mathrm{PVP}=83 / 17$ & 172.6 & 52 \\
Residual PVDF from PVDF $/ \mathrm{PVP}=67 / 33$ & 171.8 & 48 \\
Residual PVDF from PVDF/PVP $=50 / 50$ & 171.9 & 54 \\
Residual PVDF from PVDF/PVP $=33 / 67$ & 172.6 & 49 \\
\hline
\end{tabular}
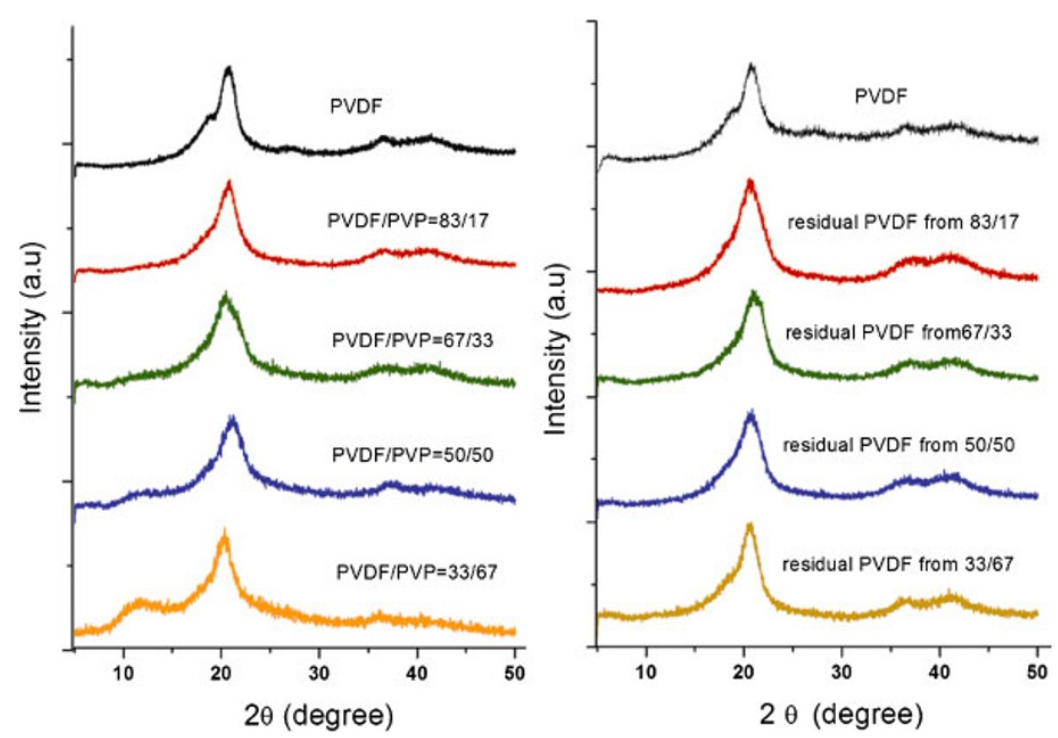

Figure 3. WAXD diagram of as-deposited PVDF/PVP fibers with various blending ratios and their residual PVDF fibers after removal of PVP.

fiber diameter of as-deposited PVDF/PVP fiber from $\mathrm{PVDF} / \mathrm{PVP}=67 / 33$ blend decreased from 752 to $525 \mathrm{~nm}$ by removal of PVP. This decrease may be caused by formation of porous structure in fiber and shrinking of fiber during immersion in water.

The BET specific surface areas of residual PVDF fiber were $4.49 \mathrm{~m}^{2} / \mathrm{g}$ (from PVDF $/ \mathrm{PVP}=83 / 16$ ), $28.54 \mathrm{~m}^{2} / \mathrm{g}($ from PVDF $/ \mathrm{PVP}=67 / 33), 15.21 \mathrm{~m}^{2} / \mathrm{g}$ (from $\mathrm{PVDF} / \mathrm{PVP}=50 / 50$ ), and $8.25 \mathrm{~m}^{2} / \mathrm{g}$ (from $\mathrm{PVDF} / \mathrm{PVP}=33 / 67)$, respectively. The mercury porosimetry measurements supported that the surface of residual PVDF fiber contains pore around $30 \mathrm{~nm}$ in diameter.

\section{Characterization of Crystalline Structure}

The melting point and crystallinity of nanofiber determined by DSC measurements are summarized in Table I. The increase in PVP blending ratio decreased the melting point and crystallinity of as-deposited PVDF/PVP fiber (melting point of PVP and PVDF are 96.7 and $172{ }^{\circ} \mathrm{C}$, respectively). After removing of PVP, the melting point and crystallinity of residual
PVDF nanofiber shifted to those of PVDF. These results indicate that the presence of PVP inhibited the crystallization of PVDF in the blends during ESD. The same trend was reported by Alfonso et al. for the PVDF/PVP cast film. ${ }^{20}$

Figure 3 shows the WAXD diagram of as-deposited PVDF/PVP fiber with various blending ratios and their residual PVDF fiber after removal of PVP. The as-deposited PVDF contains a mixture of $\alpha$-phase and $\beta$-phase crystal. The 2 theta peaks around $19.3^{\circ}$ and $20.3^{\circ}$ correspond to $\alpha$-phase and $\beta$-phase crystals, respectively. Removal of PVP enhanced the formation of $\beta$-phase crystal structure.

Figure 4 shows the typical FT-IR spectra of as-deposited PVDF/PVP fiber and its residual PVDF fiber after removal of PVP. The peaks around 766, 840, and $1667 \mathrm{~cm}^{-1}$ correspond to $\alpha$ - and $\beta$-phase PVDF and carbonyl group of PVP, respectively. After removal of PVP, the peak from carbonyl group of PVP shifted to lower wavelength. This indicates that the hydrogen bonding between PVDF and PVP molecule is weakened by removal PVP. Here, the ratio of 


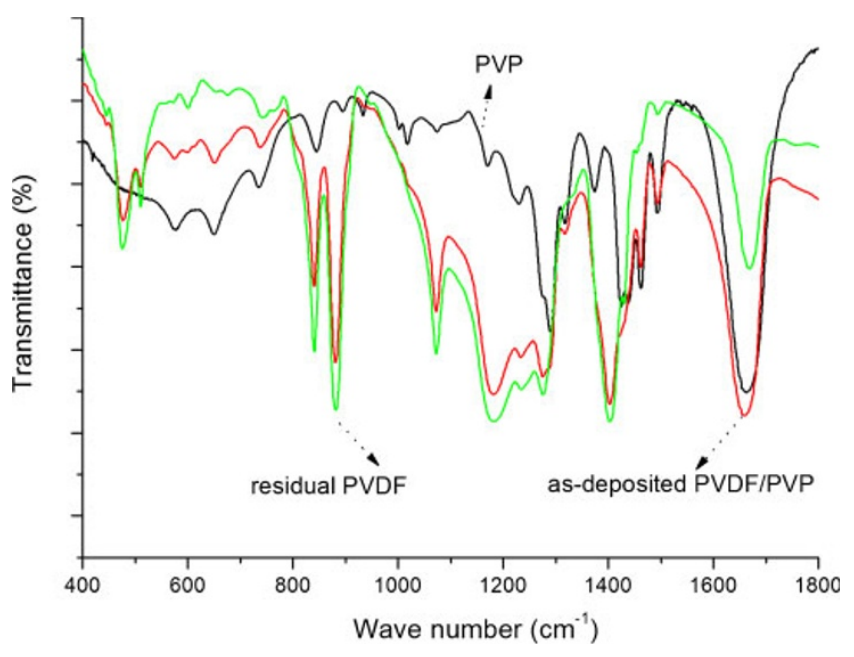

Figure 4. FT-IR spectra of as-deposited PVDF/PVP fibers with the blending ratio $\mathrm{PVDF} / \mathrm{PVP}=67 / 33$ and its residual PVDF fibers after removal of PVP.

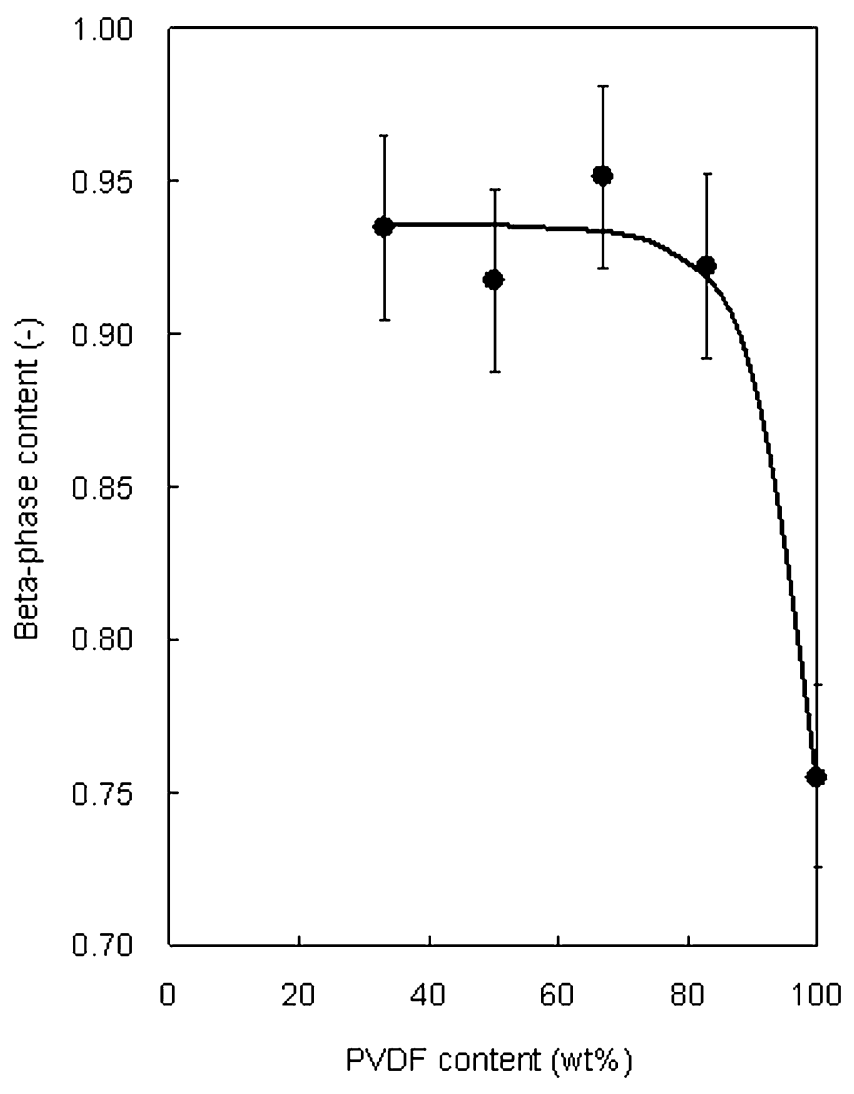

Figure 5. $\beta$-phase crystal fraction of residual PVDF from $\mathrm{PVDF} / \mathrm{PVP}$ blend with various compositions.

the $\beta$-phase to $\alpha$-phase is calculated from the absorbance of the respective vibration band peaks FT-IR spectra ( $\beta$-phase: $840 \mathrm{~cm}^{-1}$ and $\alpha$-phase: $\left.766 \mathrm{~cm}^{-1}\right){ }^{8}$

Figure 5 shows $\beta$-phase crystal content of the residual PVDF fiber from PVDF/PVP blend with various blend compositions. All residual PVDF nanofiber showed high content of $\beta$-phase crystal structure
(>90\%). Hanada et al. reported that the FloryHuggins interaction parameter $\chi_{12}$ for the PVDF/ PVP showing very huge value $\mathrm{ca} .-0.36$ at $160^{\circ} \mathrm{C}$ below the PVDF content of $80 \mathrm{wt} \%$, compared with the one for PVDF/PMMA of -0.30 . On the other hand, it showed anomaly $c a .0 .8$ at the PVDF content of $90 \mathrm{wt} \% .^{21}$ Therefore, the addition of the small amount of PVP decreased the $\chi_{12}$ drastically, and such strong compatible interaction prevents the formation of TGTG-conformational segments which grow up to the nucleus of the $\alpha$-phase crystalline and the TTconformation for $\beta$-crystalline forms preferably. In addition, the formation of high (but incomplete) $\beta$ phase crystal structure would be explained by the remained of PVP. The peak from carbonyl group remained in PVP was observed at $1675 \mathrm{~cm}^{-1}$ for all residual PVDF nanofiber.

\section{CONCLUSION}

In the present study, porous nanofibers were prepared by ESD from PVDF/PVP blends and subsequent selective removal of PVP. The effects of blending ratio of PVDF/PVP and selective removal of PVP on formation of the pore and crystal structures of residual PVDF fibers were investigated. Specific surface area of residual PVDF fiber depended on the blending ratio of $\mathrm{PVDF} / \mathrm{PVP}$ (The highest BET surface area of residual PVDF fiber was $28.54 \mathrm{~m}^{2} / \mathrm{g}$ ). All residual PVDF nanofibers, on the other hand, showed a high content of $\beta$-phase crystal structure (>90\%). The high $\beta$-phase content and porous PVDF is a promising material for high efficiency filter media.

\section{REFERENCES}

1. P. Gibson, H. Schreuder-Gibson, and D. Rivin, Colloids Surf., A, 187-188, 469 (2001).

2. V. Z. Mordkovich, Theor. Found. Chem. Eng., 37, 429 (2003).

3. G. Zhang, W. Kataphinan, R. Teye-Mensah, P. Katta, L. Khatri, E. A. Evans, G. G. Chase, R. D. Ramsier, and D. H. Reneker, Mater. Sci. Eng., B, 116, 353 (2005).

4. R. J. Tseng, J. Huang, J. Ouyang, R. B. Kaner, and Y. Yang, Nano Lett., 5, 1077 (2005).

5. S. Zhang, Nat. Biotechnol., 21, 1171 (2003).

6. S. Virji, R. B. Kaner, and B. H. Weiller, J. Phys. Chem. B, 110, 22266 (2006).

7. Z. Ma, M. Kotaki, R. Inai, and S. Ramakrishna, Tissue Eng., 11, 101 (2005).

8. M. Nasir, H. Matsumoto, T. Danno, M. Minagawa, T. Irisawa, M. Shioya, and A. Tanioka, J. Polym. Sci., Part B: Polym. Phys., 44, 779 (2006).

9. L. Zhang and Y.-L. Hsieh, Nanotechnology, 17, 4414 (2006).

10. Y. Z. Zhang, Y. Feng, Z.-M. Huang, S. Ramakrishna, and C. T. Lim, Nanotechnology, 17, 901 (2006). 
11. S. Megelski, J. S. Stephens, D. B. Chase, and J. F. Rabolt, Macromolecules, 35, 8456 (2002).

12. J. T. McCann, M. Marquez, and Y. Xia, J. Am. Chem. Soc., 128, 1436 (2006).

13. H. Kawai, Jpn. J. Appl. Phys., 8, 975 (1969).

14. B. Mohammadi, A. A. Yousefi, and S. M. Bellah, Polym. Test., 26, 42 (2007).

15. Y. Ye, Y. Jiang, Z. Wu, and H. Zeng, Integrated Ferroelectrics, 80, 245 (2006).

16. M. Nasir, H. Matsumoto, M. Minagawa, A. Tanioka, T. Danno, and H. Horibe, Polym. J., 39, 670 (2007).

17. M. Khayet, C. Y. Feng, K. C. Khulbeb, and T. Matsuura,
Polymer, 43, 3879 (2002).

18. K. Ishizaki, S. Komarneni, and M. Nanko, in "Porous Material: Process Technology and applications," Kluwer Academic Publisher, London, 1998, pp 204-214.

19. W. Sae-lim, W. Tanthapanichakoon, and C. Kanaoka, J. Aerosol Sci., 37, 228 (2006).

20. G. C. Alfonso, A. Turturro, M. Pizzoli, M. Scandola, and G. Ceccorulli, J. Polym. Sci., Part B: Polym. Phys., 27, 1195 (1989).

21. T. Hanada and Y. Ando, in "the series of the natural science and engineering," The Bulletin of Tokyo Kasei Gakuin University, 41, 2001, p 77. 